\title{
Multi-factor Constrained Analysis Method for Geological Hazard Risk
}

\author{
Kunwang Tao, Liang Wang, and Xinlin Qian
}

\begin{abstract}
Because of the complexity and uncertainty of geological disasters, using GIS technology to take grid transformation for the analyze area, research on the mechanisms and principles of geological disasters were conducted, elevation, slope, lithology, faults, etc. as an evaluation factor, geological disasters risk assessment carried out with mathematical algorithms. Xinjiang Uygur Autonomous Region in the Ili River basin as the experimental area, create $500 * 500 \mathrm{~m}$ grid covering the study area. With GIS statistical analysis, overlay analysis, spatial analysis to do grid transform and standardization. And finally use information Act to determine the weight and comprehensive assessment. Experimental results show that the actual geological disasters occurred in the geological disaster risk analysis and other areas where a high level of probability is high, indicating that the method of geological disaster warning prediction has some practical significance.
\end{abstract}

Index Terms-Geological hazard, geographical grid, information method, statistics, risk analysis.

\section{INTRODUCTION}

A geological disaster is one of the world's biggest disasters causing damage to human life and property, and the environment. In recent years, the impact of geological disasters is more serious, and has caused widespread concern in the field of disaster prevention and mitigation by many experts and scholars. Theory and technical for the analysis of geological risk also has an increasing concern and attention by the national research institutions, research methods have also made great progress. Remote sensing, geographic information systems, mathematics and statistics and some new theories, techniques and methods continue to be introduced to the study of geological disasters [1]. Chu Hongbin et al, use method of Analytic Hierarchy Progress to calculate the comprehensive evaluation index with samples of the landslides, mudslides and other samples [2]. Chen $e t$ al., use a new method of fuzzy mathematics to do a geological hazard assessment for Shaanxi Qinling tectonic denudation of mountains and rift basin [3].

Geographical grid technology as a new method for geospatial analysis, statistical information is distributed to a certain cell grid, which is conducive for statistical data and geospatial information fusion and finding the law of the spatial distribution. In this paper, geographic grid technology was involved into geological disaster risk analysis, and we

Manuscript received October 11, 2014; revised December 29, 2014.

The authors are with Chinese Academy of Surveying and Mapping, 28 Lianhuachixi Road, Haidian District, Beijing 100830, China (e-mail: Taokw@casm.ac.cn,Wangl@casm.ac.cn, Qianxinlin@gmail.com). select the debris flow as the main research object of geological disasters. Yili river basin in xinjiang as an example, the actual situation of the study area was analyzed to establish a scientific and rational system of indicators factor. The study area was divided into $500 \times 500 \mathrm{~m}$ grid, and the evaluation of data distribution factor was distributed into grid cells. Finally factor weights were determined by using information law to achieve the analysis of geological disaster risk, and each grid analysis results were showed in a hierarchical grading thematic map.

\section{The ANALYsis PROGRESS FOR GEOLOGICAL DisASTER}

According to information model, specific research process of geological disaster risk analysis can be divided into four steps: first to establish appropriate evaluation factor system; second grid transformation of research area, and the index data layers of evaluation factors were distributed into grid cells; third, according to the evaluation index factor system, calculate the impact factor for each data type on the information provided by the geological disaster; fourth, according to the amount of information of each influencing factor for each data class, classified for each factor, and ultimately the geological disaster risk assessment map can be generated.

\section{A. Final Stage Establishment of Evaluation Index System}

Although the specific types of geological disasters mudslides, landslides are so different, but for geological disasters, its happen and development share some common characteristics, so the index factor in the selection process should avoid differences, and try to choose a common factor, to build a scientific and standardized system for the index factor[4]. Therefore, this paper based on the actual situation of the study area, and considering two aspects of environmental hazards and disaster leading factors to build index factor system. As follows:

1) Elevation: landslides, mudslides will slide along the lower face of internal slide by the action of gravity. So elevation is an important factor for the happening of landslides, mudslides and other geological disasters.

2) Slope: slope is the basic natural geographic features, it is also an important factor for the development of landslides, and it has a direct impact on the stability of slopes. Under certain conditions, the steeper the slope, the easier for the loose bulk material of earth surface to go with the rainwater, under the effect of geological disasters mudslides, landslides, etc. [5].

3) Fault structure: regional faults, is often an important factor triggered geological disasters. Fragmentation will 
affect the stability of the fracture layers of rock slope, so the fault geological structure will affect geological disasters within a certain distance.

4) Lithology formation: Formation lithology is the material basis of all geological disasters. For the formation that earth-rock properties is relatively weak, the structure is loose and not easy to drainage, is easy to produce the geological disasters such as landslide and debris flow.(5) Land use and road network density: they reflect the relationship between human activity and geological disasters. Human-building activities can undermine the stability of the surface itself. Such as the construction of roads, land reclamation, construction of farmland water conservancy and other activities will affect geological disasters.

\section{B. Grid Transformation of the Study Region}

According to the actual situation of the study area, the size of the grid as $500 \mathrm{~m} \times 500 \mathrm{~m}$ is set, using spatial overlay analysis, the index data layers of evaluation factors are distributed in a grid cell. In the overlay process, a factor layer will conclude multiple categories of information, according to the "largest" principle [6], by using the GIS statistical analysis function, the category area will be set an area properties for each grid, the maximum area value attribute information is assigned to the grid (show in Fig. 1), and then the grid information is achieved.

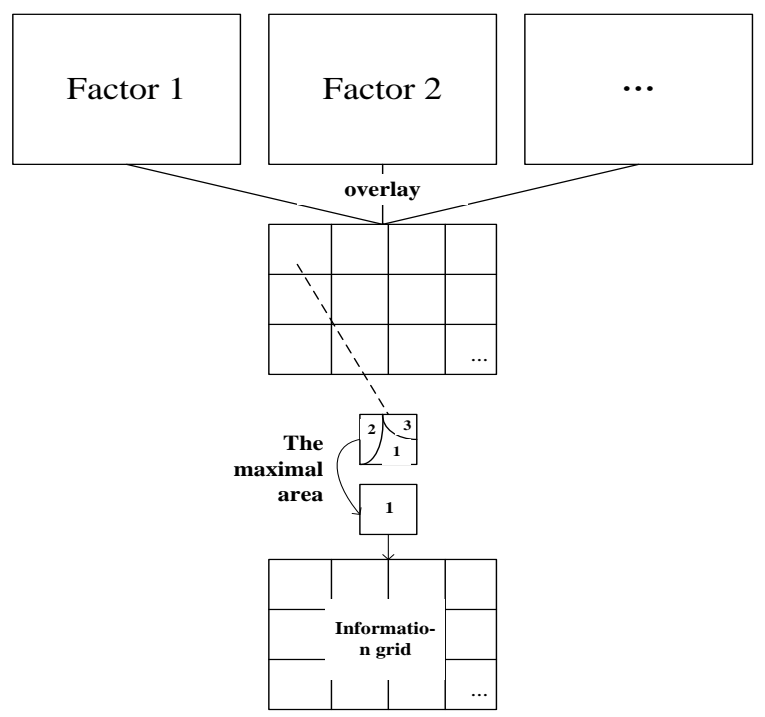

Fig. 1. Sketch map of grid transformation for the study area.

\section{Calculation of Impact Factor's Information}

For the geological Disaster Risk analysis, geological disaster phenomena $(\mathrm{Y})$ is affected by many factors, the importance of the role various factors played in the affection is different, and the same to their nature. In a variety of geological environments, there will always be a 'best combination" for various factors, which contribute the most part of geological disasters. Therefore, the regional geological hazard elements should be took emphasis on the "best combination of factors" rather than staying on a single factor. From the Information predictable view: The generation of geological disasters or not is related with the quantity and quality of information that obtained in the procedure of the prediction [7], and it is measured by the amount of information:

$$
I\left(Y, X_{1}, X_{2} \ldots \ldots X_{n}\right)=\operatorname{Ln}\left[P\left(Y, X_{1}, X_{2}, \ldots, X_{n}\right) / P(Y)(1)\right.
$$

Under normal circumstances, due to many factors in geological disasters, the appropriate combination of factors are particularly large, the number of samples is often limited, so using a simplified model of single-factor information step by step is adopted, and then integrated overlay analysis, appropriate information model is rewritten as:

$$
I\left(X_{i}, H\right)=\operatorname{Ln}\left[\left(\frac{N_{i}}{N}\right) /\left(\frac{S_{i}}{S}\right)\right]
$$

where, $S$ is the total number of research units; $\mathrm{N}$ is total number of units in the study area has geological disasters occur; $\mathrm{Si}$ is the number of elements contained $\mathrm{Xi}$; $\mathrm{Ni}$ is containing $X i$ factor and has undergone a number of geological disasters unit.

\section{Risk Comprehensive Assessment}

Comprehensive assessment of geological disaster risk is calculated using the weighted summation of the general model factor value and the weight values[8]. Specific formula is as follows:

$$
\text { Comprehensive Assessment }=\sum_{i=1}^{n} z_{i} \sum_{j=1}^{m} z_{i j} I_{i j}
$$

where $Z_{i}$ and $Z_{i j}$ are the factors weights of the first and the second grade. According to quantify and the weights value of each factor inside the cell, with GIS map algebra functions, risk value of geological disaster-prone degree in each cell is calculated, and then, by the cluster analysis, the data owned largest similarity was set in the same grade, the biggest difference between the data points are set at different levels. Then we can get a better statistical characteristics of the data and reveal more accurate spatial distribution pattern of geological disasters [9], so based on naturally split point method, the degree of risk divided into (low risk, lower risk, high hazard, higher hazard) four grades. Finally, do visualization with layered color map.

\section{GeOlOGICAL HaZARD ANALYSIS}

\section{A. Situation of the Study Area}

Gongliu and XinYuan County are located in Xinjiang Ili River Basin between the Tianshan Mountains near the north branch of the mountains and the southern branch po LuoKeNu Kharg mountain, located in the $42^{\circ} 50$ ' $\sim 44^{\circ} 10^{\prime} \mathrm{N}$, $80^{\circ} 30^{\prime} \sim 83^{\circ} 10^{\prime}$, between 600 to 4000 meters above sea level, it is surrounded by mountains, west open, shaped like Kei, constitute something long, narrow north-south, east to the west of the special terrain. From west to east as the valley plains, hilly, Zhongshan belt and alpine zone, the unique topography, abundant rainfall, making frequent outbreaks of geological disasters in the region.

\section{B. Processing of Effect Factors}

According to the distribution characteristics of the Ili River 
basin topography and landslides, debris flows point, make use of specialized software ArcGIS10.0 processed the factor and display in the form of re-classification. Some indicators factor and its reclassification are shown in Fig. 2- Fig. 5.

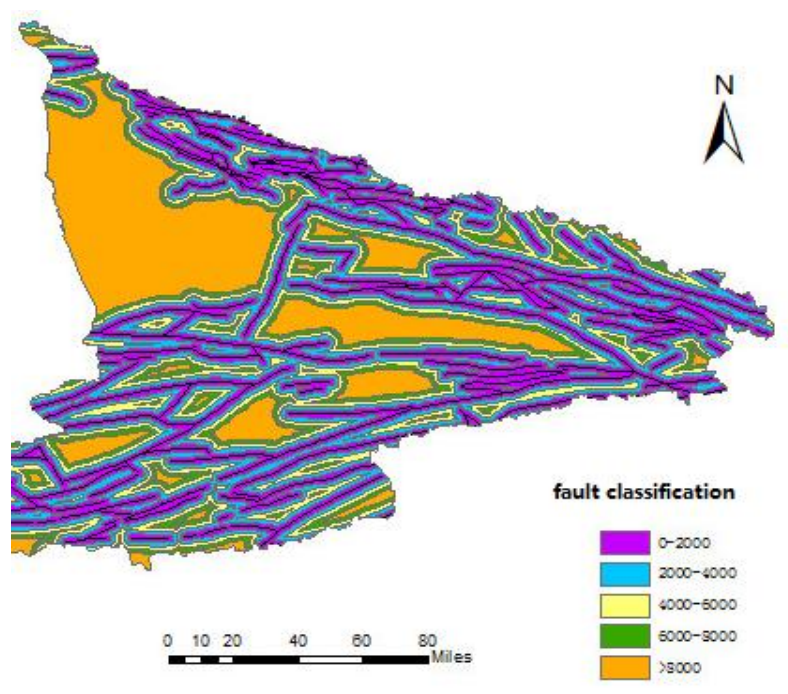

Fig. 2. Fault classification graph.

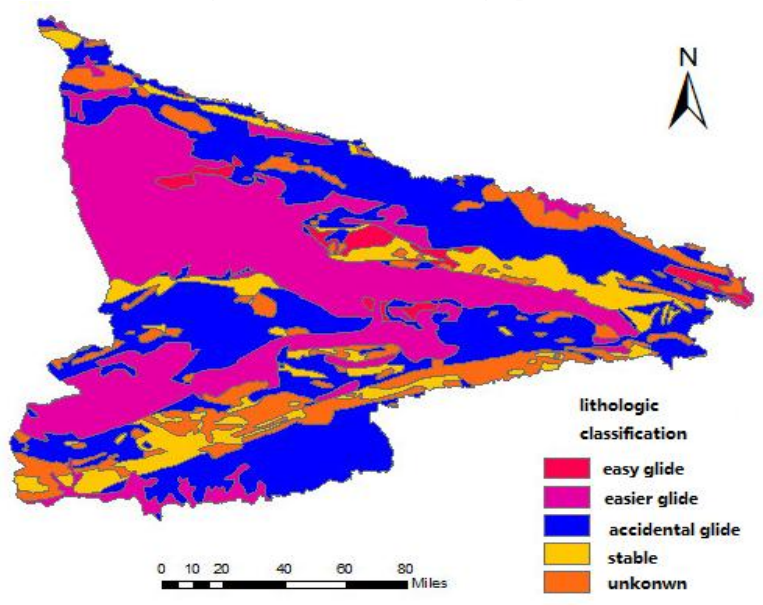

Fig. 3. Lithology classification graph.

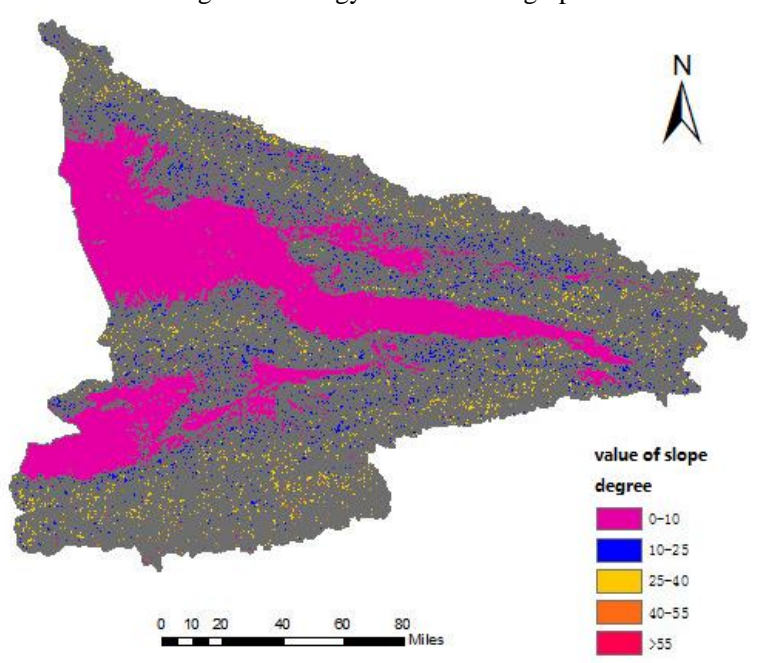

Fig. 4. Slop degree classification graph

\section{Weight Value of Effect Factors}

Based on the factor values that quantized, using information model Equation (1) and Equation (2) the information is calculated for each factor, as shown in Table I.

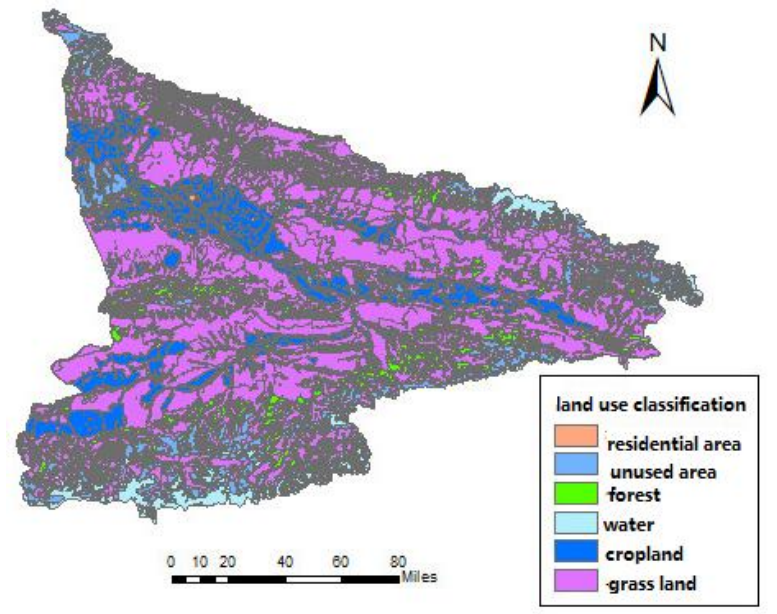

Fig. 5. Land use classification graph.

TABLE I: INFORMATION CALCULATION RESULTS

\begin{tabular}{|c|c|c|c|c|c|c|}
\hline & classification & area & $\begin{array}{l}\text { Number of } \\
\text { disaster } \\
\text { points }\end{array}$ & $\mathrm{Ni} / \mathrm{N}$ & $\mathrm{Si} / \mathrm{S}$ & information \\
\hline \multirow{5}{*}{ faultage } & 2000 & 18384.18 & 325 & 0.42 & 0.33 & 0.2319 \\
\hline & 4000 & 12687.09 & 175 & 0.23 & 0.23 & -0.0162 \\
\hline & 6000 & 7831.31 & 107 & 0.14 & 0.14 & -0.0257 \\
\hline & 8000 & 4534.00 & 59 & 0.08 & 0.08 & -0.0745 \\
\hline & $>8000$ & 11915.50 & 110 & 0.14 & 0.22 & -0.4178 \\
\hline \multirow{5}{*}{ lithology } & Easy slide & 1263.80 & 12 & 0.02 & 0.02 & -0.3897 \\
\hline & Easier slide & 19506.11 & 150 & 0.19 & 0.35 & -0.6005 \\
\hline & Few slide & 21879.11 & 405 & 0.52 & 0.40 & 0.2779 \\
\hline & stable & 5611.45 & 119 & 0.15 & 0.10 & 0.4139 \\
\hline & uncertain & 7091.60 & 90 & 0.12 & 0.13 & -0.0995 \\
\hline \multirow{5}{*}{$\begin{array}{l}\text { Slope } \\
\text { degree }\end{array}$} & $0-10$ & 21483.65 & 141 & 0.18 & 0.39 & -0.7571 \\
\hline & $10-25$ & 15625.55 & 356 & 0.46 & 0.28 & 0.4875 \\
\hline & $25-40$ & 14722.70 & 251 & 0.32 & 0.27 & 0.1975 \\
\hline & $40-55$ & 3364.51 & 28 & 0.04 & 0.06 & -0.5196 \\
\hline & $>55$ & 261.42 & 0 & 0.00 & 0.00 & $-\infty$ \\
\hline$\cdots$ & $\cdots$ & $\ldots$ & $\cdots$ & $\ldots$ & $\ldots$ & $\ldots$ \\
\hline
\end{tabular}

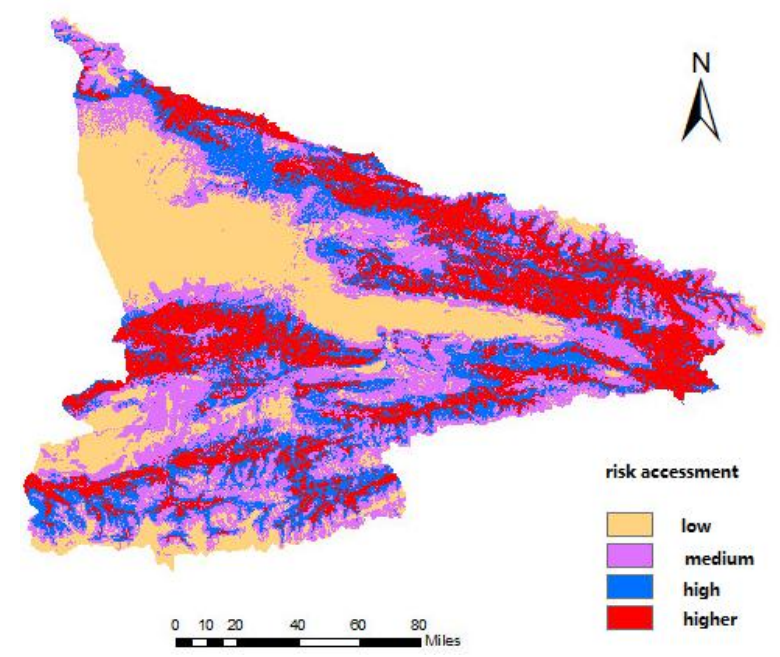

Fig. 6. Results of risk assessment.

\section{Results of Risk Assessment}

According to the Equation (3), the geological disaster risk value of each cell network will be calculated to make a 
comprehensive assessment, and then expressed in thematic map visualization analysis results, shown in Fig. 6.

The geological disaster risk analysis chart of Yili River basin can be seen: landslides in the high-risk area are mainly in northern Yili River basin, central and southwestern mountains; higher risk areas are mainly located in the narrow region near the eastern and high-risk areas; concentrated in low-risk areas and low risk areas in the central plains. This shows that the risk is significantly higher than the mountain plains, due to mountainous terrain, big elevation, steep slope, experiencing snow and rains, encountering temperatures, snow melt or heavy rainfall in flood season, in under the action of the melted snow, rain and with the role of complex terrain can easily lead to landslides.

In addition we use the geological disasters of the last two years as an example, the number of disasters each point separately statistics contained dangerous levels of the total number of points in the history of disaster proportions, concrete results are shown in Table II below:

TABLE II: STATISTICS OF DANGEROUS GRADE

\begin{tabular}{lll}
\hline Dangerous grade & $\begin{array}{l}\text { Number of disaster } \\
\text { points }\end{array}$ & percent \\
\hline Low dangerous & 2 & $1.32 \%$ \\
Medium dangerous & 7 & $4.64 \%$ \\
Little high dangerous & 45 & $29.80 \%$ \\
High dangerous & 97 & $64.24 \%$ \\
\hline
\end{tabular}

Statistics from the danger level of statistical results, and a higher proportion of high-risk area for 94.04 percent of disaster point, the proportion of low risk zone disaster point is $4.64 \%$, while the proportion of low-risk regional disaster point is $1.32 \%$, most points are included in the area of disaster risk areas and higher in high-risk.

\section{CONCLUSION}

This paper is based on the research area of Xinjiang Ili River Basin, make use of geographic grid technology to subdivision area, set up a system of geological hazard assessment factor, combined the statistical analysis and spatial analysis algorithms to establish a landslide early warning forecast model as an example of geological disasters. According to the predicting model, warming forecast Ili River Basin geological disasters. The results show that network GIS technology is feasible and practical significance for the study of geological disasters.

However, due to the complexity of geological disaster forecast, Warning prediction models still need further improvement, correctness and scientificity of the models need further validation.

\section{REFERENCES}

[1] X. Liu, J. J. Zhan et al., "Design and application of geo-hazard early-warning model," Journal of Engineering Geology, vol. 16, pp. 342-346, Sep. 2008.

[2] H. Chu, H. Mu, and J. Wang, "Application of analytic hierarchy process on zoning hazard degree of geologic disaster in taihang mountain region," The Chinese Journal of Geological Hazard and Control, vol. 14, pp. 126-128, Sep. 2003.

[3] X. Chen, Z. Duan, and F. Zhao, "Geological hazard risk assessment based on fuzzy mathematics," The Chinese Journal of Geological Hazard and Control, vol. 22, pp. 92-94, Sep. 2011.

[4] Y. Miao, "Study on geological hazards risk zoning base on GIS and logistic," M.S. thesis, Chang'an Univ., Xi'an, China, 2010.

[5] J. Du, Rainfall Forecast and Early Warning of Geological Disaster, 1st ed. Beijing, China, Beijing Science Pres, 2010, pp. 50-58.

[6] L. Gong, "Analysis of regional eco-security evaluation and spatial evaluation based on grid GIS - A case study of Dalian Ganjingz," M.S. thesis, Liao Ning Normal Univ., Liao Ning, China, 2012.

[7] Y. Liu and M. Yang, "On the information content model of geological hazard assessment in the area of falling of chongqing," Journal of Chongqing Normal University(Natural Science), vol. 29, pp. 35-388, June 2012.

[8] M. Fang, J. Zhang, and Z. Xu, "Landslide susceptibility zoning study in lanzhou city based on gis and logistic regression model," Remote Sensing Technology and Application, vol. 26, pp. 846-852, Dec. 2011

[9] Y. Liao, F. Zhao, Z. Wang et al., "Spatial pattern analysis of natural disasters in China from 2000 to 2011," Journal of Catastrophology, vol. 28 , pp. 55-60, Oct. 2013

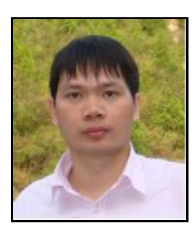

Kunwang Tao was born in Guangxi of Chinese in 1978 He received his bachelor's degree at Hohai University in 2000 , with the major of surveying engineering, and $\mathrm{He}$ received his master's degree at Chinese Academy of Surveying and Mapping (CASM), in 2006.

He used to work in the field of surveying engineering, water conservancy project. And now he is working as a researcher of Chinese Academy of Surveying and Mapping (CASM), his main research interests include geographic information in spatial analysis model, including network geographic information services, the government geographic information system, etc.

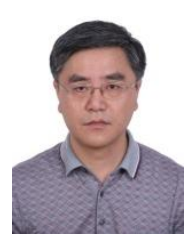

Liang Wang was born in Heilongjiang Province of China in 1963. He received his B.S. in cartography from Nanjing University. He has been a professor at Research Centre of E-Government GIS, Chinese Academy of Surveying and Mapping since 2001. His research interests include geographic information visualization, geographic information service for emergency management.

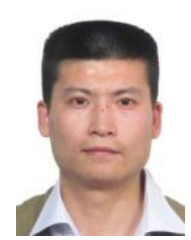

Xinlin Qian was born in Hubei Province, China, in 1980. He received his B.S., M.S. and Ph.D. degrees from the Wuhan University in 2002, 2006 and 2011, respectively. His research interests include spatial database, web-based geographical information systems. 